\title{
Jan Peters (éd.), Peter Hagendorf. Tagebuch eines Söldners aus dem Dreißigjährigen Krieg
}

Göttingen : V\&R unipress (Herrschaft und soziale Systeme in der Frühen Neuzeit, 14), 2012, 238 p., 29,90€

\section{Claire Gantet}

\section{OpenEdition}

\section{Journals}

Édition électronique

URL : http://journals.openedition.org/ifha/7658

DOI : $10.4000 /$ ifha. 7658

ISSN : 2198-8943

Éditeur

IFRA - Institut franco-allemand (sciences historiques et sociales)

\section{Référence électronique}

Claire Gantet, « Jan Peters (éd.), Peter Hagendorf. Tagebuch eines Söldners aus dem Dreißigjährigen Krieg », Revue de l'IFHA [En ligne], Date de recension, mis en ligne le 15 décembre 2013, consulté le 22 septembre 2020. URL : http://journals.openedition.org/ifha/7658 ; DOI : https://doi.org/10.4000/ifha. 7658

Ce document a été généré automatiquement le 22 septembre 2020.

C)IFHA 


\section{Jan Peters (éd.), Peter Hagendorf. Tagebuch eines Söldners aus dem Dreißigjährigen Krieg}

Göttingen : V\&R unipress (Herrschaft und soziale Systeme in der Frühen Neuzeit, 14), 2012, 238 p., 29,90€

\section{Claire Gantet}

L'édition en 1993 d'un diaire d'un mercenaire de la guerre de Trente ans trouvé au hasard dans les fonds de la Bibliothèque d'État de Berlin par Jan Peters eut une immense résonance dans la recherche historique. Jan Peters livrait les annotations non d'un chef de guerre, mais d'un homme du peuple, durant 25 années de guerre, dans un contexte historiographique caractérisé par l'affirmation de la micro-histoire et les débats sur la confessionnalisation. Entre 1625 et 1649, ce mercenaire parcourut, à vol d'oiseau, $22500 \mathrm{~km}$ en passant par l'Italie, l'Allemagne, les Pays-Bas autrichiens et la France. La longueur de son service confirme la transition entre les armées de mercenaires et les armées permanentes : il fut de fait un soldat de métier et connut une certaine ascension dans l'armée d'infanterie. Durant ces années, il ne perçut que deux fois une solde, lors de son engagement en 1625 et lorsqu'il fut congédié et remis à la société civile en 1649. Entre ces deux dates, il dépendit sans cesse du butin, permis, voire encouragé par les autorités militaires faute de paiement régulier. Dans un monde marqué du sceau de l'inconstance, ce mercenaire déploya une énergie extraordinaire dans ses stratégies de survie. Le sentiment d'appartenance au groupe armé - face aux populations civiles, même si elles étaient dans le même camp politique - y joua un grand rôle, la seule action individuelle reconnue étant le butin. Le sentiment familial y contribua aussi, la première femme du mercenaire, puis sa deuxième après son veuvage le suivant parmi le trousseau dont les annotations aident à retracer le fonctionnement. Pour survivre, ce mercenaire n'hésita pas à changer de camp : combattant d'abord dans des troupes impériales de Pappenheim, il s'engagea par la suite chez les Suédois puis retourna enfin chez les Impériaux. Ses annotations le montrent tout à fait conscient de ses choix et des camps qu'ils incarnent. De même pour ce qui est de la religion qui représentait un réel refuge et de réelles valeurs pour lui. Or s'il savait très bien 
identifier les catholiques et les protestants, aucun indice, dans tous les feuillets de son diaire, ne permettre de déceler son parti confessionnel.

Dix-neuf ans après la première parution, ce texte garde tout son intérêt, ce qui justifie en soi une nouvelle édition. Cette nouvelle édition comporte néanmoins deux faiblesses de taille. Jan Peters a laissé la source, sa présentation (à l'exception de la postface historiographique) et l'apparat critique identiques, à une exception près, indiquée dès le titre. Dorénavant, ce mercenaire, anonyme en 1993, porte un nom : Peter Hagerdorf. C'est un élève de Jan Peters, Marco von Müller, qui dans sa maîtrise (Magisterarbeit, consultable en ligne sous le lien http://mvonmueller.de/ Magisterarbeit_MvM_01_02_2005.pdf) a établi son identité en croisant les actes de naissance de certains de ses enfants à d'autres sources. La deuxième remarque a trait au format choisi pour cette réédition. Un portail d' « égo-documents » ou écrits du for privé de l'Allemagne moyenne à l'époque de la guerre de Trente ans existe déjà (http:// www.mdsz.thulb.uni-jena.de/sz/gesamt.php). Une publication électronique dans ce portail ou en lien avec lui aurait permis de considérablement augmenter et renforcer les notices explicatives et documents complémentaires, tout en accroissant la "visibilité » de ce type de sources auprès d'un public plus vaste que celui des spécialistes de la guerre de Trente ans. Ces faiblesses de l'édition, toutefois, n'enlèvent évidemment rien à la qualité exceptionnelle de la source.

INDEX

Index chronologique : Frühe Neuzeit

Thèmes : Mentalitätsgeschichte

\section{AUTEUR}

\section{CLAIRE GANTET}

Université Paris I - Akademie der Wissenschaften, Göttingen 